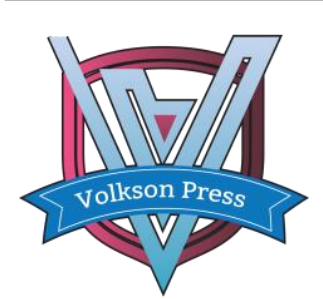

Contents List available at VOLKSON PRESS

Mechanical and Control Engineering (MCE)

DOI : http://doi.org/10.26480/wsmce.01.2017.48.51

\title{
DESIGN AND SIMULATION OF IMPROVED PI NEURON CONTROL FOR PHOTOVOLTAIC INVERTER
}

\author{
Zhou Rui ${ }^{1}$, Zhang $\mathbf{Y u}^{1,2^{*}}$, Zhang Lie-ping ${ }^{1,2}$ \\ ${ }^{1}$ College of Mechanical and Control Engineering, Guilin University of Technology, Jian Gan Street, Guilin, China \\ ${ }^{2}$ Guangxi Key Laboratory of building new energy and energy saving, Guilin University of Technology, Jian Gan Street, Guilin,
China *Corresponding Author email: $17316606 @ q$.com
}

This is an open access article distributed under the Creative Commons Attribution License, which permits unrestricted use, distribution, and reproduction in any medium, provided the original work is properly cited

\section{ARTICLE DETAILS}

\section{Article History:}

Received 02 october 2017

Accepted 06 october 2017

Available online 11 november 2017

Keywords

particle swarm optimization, neural network, photovoltaic, inverter.

\section{ABSTRACT}

The algorithm of traditional double closed loop PI control has the advantages of simple structure, good robustness and high reliability, but its parameter setting is difficult, and not good at tracking changes of photovoltaic power generation system in complex nonlinear case. Aiming at the above problems, a control algorithm based on neuron PI inverter has been proposed. Neurons with proportional and integral functions are defined, thus the PI control law is fused into the neural network. The connections between neurons are improved, in order to realize the on-line adjustment of parameters, and the model does not need accurate system. The result of system simulation and experimental shows that the system using this method can track state changes quickly and adjust parameters automatically, which has strong effectiveness.

$\longrightarrow$

\begin{abstract}
1. Introduction
Sine wave AC inverter is the core device of power electronic equipment, such as photovoltaic grid connected, AC speed regulating, and so on. It has high requirements on the output waveform of AC side of inverter. In control of the solar photovoltaic linking grid, the total harmonic distribution (THD) limit of the inverter output is 5\%, and the power factor is not less than 0.95 (advance or lag). This requires the inverter to have strong anti-interference ability and fast dynamic response [1,2]. In order to obtain high quality grid connected current and better power factor, the double loop control strategy of voltage outer loop and current inner loop is generally adopted in the inverter of photovoltaic power generation system. The key to decide the effect of double closed loop control is the determination of its PI parameters. The difficulty of double closed loop control system design is to determine the parameters of the outer loop and inner loop, which needs to consider the influence of each other [3].
\end{abstract}

In view of the complexity and uncertainty of the photovoltaic inverter system, the control theory based on the traditional exact model has shown great limitations in order to realize the automatic control of the output waveform.

The PI controller is a common feedback loop component used in industrial control applications. The controller compares the collected data and the reference value, then this difference is used to calculate the input value, the new input value is to make the system data reaching or maintaining at the reference value. It is a linear control law in essence, and has weaknesses that are only applicable to linear SISO systems and are poorly controlled in complex systems [4].

In order to achieve better results, using the traditional double closed loop control method needs to establish an accurate system model, and determine the appropriate PI parameters through the trial and error method [5]. However, the system matrix, the closed loop characteristic value and the dynamic response can be changed due to the load change or the DC side voltage sudden change in the photovoltaic power generation system, which makes the parameters difficult to adapt to the change of the system. Especially for the nonlinear characteristics of photovoltaic power generation system, the modeling process is complex, the parameters are difficult to test, and it is difficult to achieve real-time adjustment of parameters [6].
To solve these problems, an improved control algorithm based on PI neuron is proposed. Neurons with proportional and integral functions are defined. The number of PI neurons, the connection mode and the initial value of connection weights are determined according to the PI control law. The connection between neurons is improved, adjust the weights and parameters in real time according to the change of system error, and starts online learning when system running. The parameters are adjusted according to historical values to achieve better control effect, to a certain extent, independent of the model of the system.

\section{PI NEURON CONTROL}

PI neuron control is based on neurons defined with the proportion respectively and integral functions, which fuses the PI control law into the neural network. The number of neurons, the connection mode and the initial value of link weights of PI neurons are determined according to the basic principle of PI control law [7]. Because its initial value is determined according to the basic principle of PI control law, it can accelerate its convergence speed and is not easy to fall into the minimum point. More importantly, the initial value of the network weights can be determined by using a large number of empirical data from the existing PI control, so that the control system maintains initial stability, and the global stability of the system becomes possible. Using PI neuron algorithm, we can use "no teacher" learning method, to do online self-learning and adjustment according to the control effect, so that the system can performance well. The control system flow and structure of PI neuron are shown in Figure.

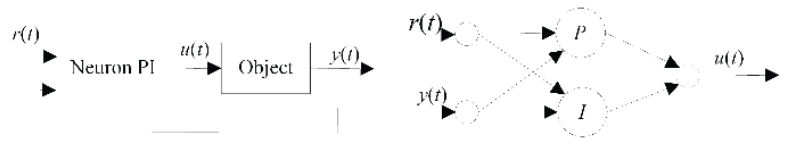

Figure 1: System Flowchart and Structure of PI Neuron 


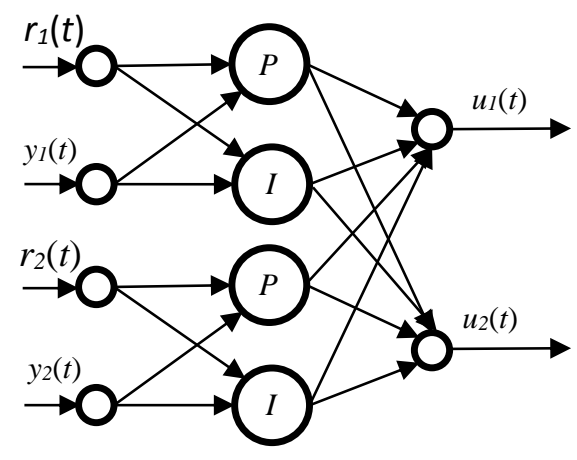

Figure 1: Structure of PI Neuron with Multiple Input and Output

Figure 1 is a PI neuron architecture with multiple inputs and outputs. At present, the neuron models which are widely used only consider the static characteristics of neurons, and only regard neurons as a unit with static input and output mapping relation, which can only deal with static information [8]. The dynamic information processing is usually carried out through the dynamic structure of the interconnection of neural networks. PI neurons, not only the proportion of yuan with static nonlinear mapping function, and the dynamic information of the integral. In PI neurons, there are not only proportional elements with static nonlinear mapping function, but also integral elements which can process dynamic information.

\section{DESIGN OF THE CONTROLLER}

Increasing the $\mathrm{K}_{\mathrm{P}}$ value in PI can improve the system adjustment rate, and may cause oscillation of control system. The purpose of increasing $\mathrm{K}_{\mathrm{I}}$ value is to reduce the steady-state error, but can increase the model transition time [9]. Therefore, the traditional PI control method is difficult to meet the control requirements of the complex photovoltaic inverter system. A controller is designed taking the advantage of online learning through neural network to adjust the parameters of the PI parameter, and the adaptability of the controller is greatly enhanced.

According to the structure of double closed loop PI control system and Figure 1, the $r_{1}(t)$ is reference waveform of load voltage. The $y_{1}(t)$ is load voltage. There is no exact current reference waveform, so the $r_{2}(t)$ is 0 . The $y_{2}(t)$ is capacitor current. Variables above are used as the four inputs, and the output is used as a PWM control waveform.

The P neuron of voltage loop is described as the following output model:

$n e t_{1}=\sum_{i=1}^{2} w_{i \mathrm{P}} x_{i}$

In the formula, $w_{i \mathrm{P}}$ is the weight of the ith input to the P neuron, according to the experience, the initial value should be $[1 ;-1], x_{i}$ is the ith input, namely $r_{1}(t)$ and $y_{1}(t)$.

The output model of I neuron of voltage loop is:

$n e t_{2}(t)=n e t_{2}(t-1)+\sum_{i=1}^{2} w_{i \mathrm{I}}(t) x_{i}(t)$

The P neurons of the feedback of the current loop are similar to(1), and can be written as:

$n e t_{3}=\sum_{i=1}^{2} w_{i \mathrm{P} 2} x_{2 i}$

In the formula, $w_{\text {iP2 }}$ is the weight of the ith input to the $\mathrm{P}$ neuron of the current loop, $x_{2 i}$ is the ith input of the current loop.

The output layer $u(t)$ is:

$u(t)=\sum_{j=1}^{3} w_{j}(t) n e t_{j}(t)$
In the formula, $w_{j}$ is the weight of the jth hidden layer node to the output layer, which actually represents the PI parameter.

In the initial stage of the control system, fast response speed is required, and the $K_{p}$ value should be increased, but, if the value is too large, the system will overshoot. Therefore, when the output value of the control system is close to the input value, the $\mathrm{K}_{\mathrm{p}}$ value should be reduced, so the $\mathrm{K}_{\mathrm{p}}$ value can be designed directly proportional to the absolute value of $e(t)$, that is:

$$
\begin{gathered}
w_{1}=0.8 w_{1}^{*}+0.2 w_{1}^{*} \tan \operatorname{sig}\left(\left|x_{1}-x_{2}\right|\right) \\
\operatorname{tansig}(x)=\frac{1-\mathrm{e}^{-x}}{1+\mathrm{e}^{-x}}
\end{gathered}
$$

In the formula, $w_{1}^{*}$ is the Original weight of $w_{1}$. The function tansig makes the error changing in the range of -1 to 1 , that makes $K_{p}$ can be adjusted according to the error based on the original parameter, and ensure that the $\mathrm{K}_{\mathrm{p}}$ value is not too small or too large.

Defining the error function:

$E(t)=\frac{1}{2}[r(t)-y(t)]^{2}$

The network input error is a function of the weight of each layer, and the adjustment of the weight can change the error $E(t)$. The principle of adjusting weights should make the error decrease continuously, so the gradient descent method can be used to make the adjustment of the weights proportional to the gradient descent of error, that is:

$\Delta w_{j}(t)=-\eta \frac{\partial E(t)}{\partial w_{j}(t)}+\alpha \Delta w_{j}(t-1)$

In the formula, $\eta$ is the learning rate; $\alpha$ is the momentum factor, the general value is about 0.0002 .

Because:

$$
\frac{\partial E(t)}{\partial w_{j}(t)}=\frac{\partial E(t)}{\partial y(t)} \cdot \frac{\partial y(t)}{\partial u(t)} \cdot \frac{\partial u(t)}{\partial w_{j}(t)}
$$

So:

$$
\frac{\partial E(t)}{\partial w_{j}(t)}=-[r(t)-y(t)] \cdot \operatorname{sgn}\left[\frac{\partial y(t)}{\partial u(t)}\right] \cdot n e t_{j}
$$

A simulation model is built based on the above, such as Figure. In the dynamic structure diagram of the inverter control system, the standard voltage waveform, load voltage, capacitor current and so on are used as input of PI neuron controller, and the output is connected to the PWM generator to achieve feedback control effect.

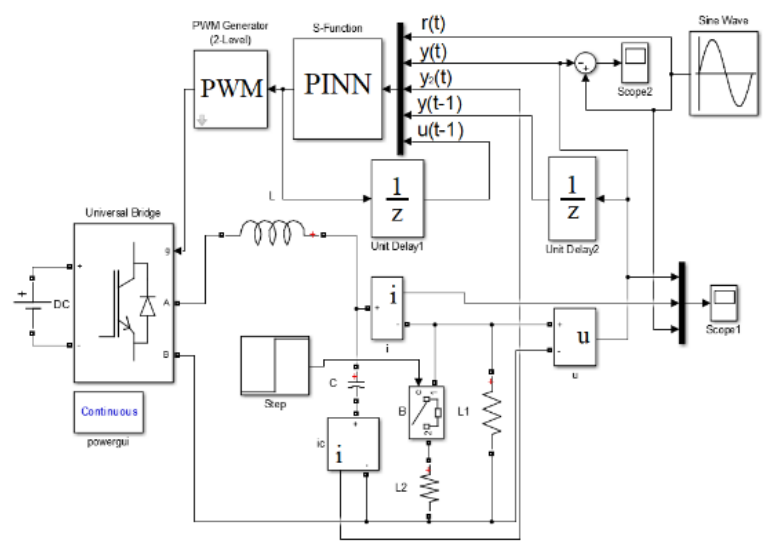

Figure 3: Simulation Model of PI Neuron Controller 
In order to verify the operation effect of the above control method, a single-phase photovoltaic grid connected system is built with Simulink. The specific parameters are as follows: DC input voltage is $400 \mathrm{~V}$, rated output AC voltage of inverter is $220 \mathrm{~V} / 50 \mathrm{~Hz}$, sampling time Ts is $1 \times 10^{-5} \mathrm{~s}$, filter inductance $\mathrm{L}=330 \mathrm{H}$, filter capacitor $\mathrm{C}=33 \mu \mathrm{F}$, load $\mathrm{R}=12 \Omega$. At $\mathrm{T}=0.05 \mathrm{~s}$, a load of $12 \Omega$ and $330 \mathrm{H}$ is suddenly added. Figure 4 is the unit step response curve contrast between PI neuron control system and the traditional double closed loop PI, it can be seen from the diagram, PI neuron overshoot is small, and quickly into the steady state, and has a faster speed.
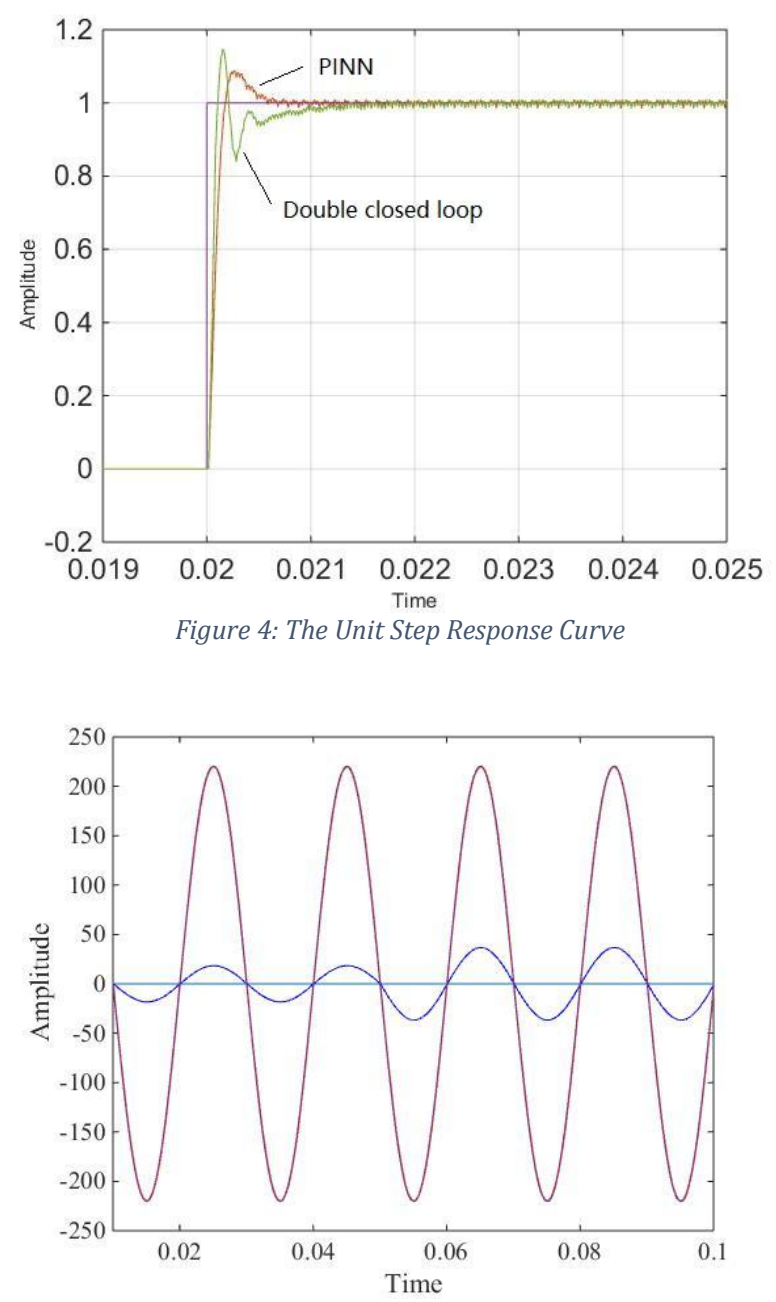

Figure 5: Waveform of neural network PI algorithm with sudden loading

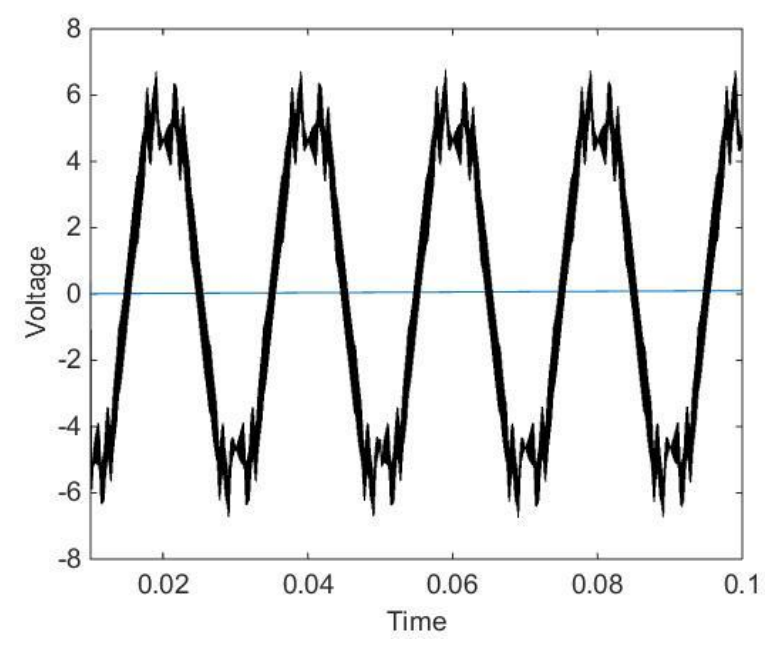

Figure 6: Error of PINN controller with sudden loading

The waveforms of the output voltage and current of the inverter controlled by the PI neuron are shown in Figure, and the error waveform is shown in Figure. The system can achieve stability quickly, and the steady state error is about $\pm 6 \mathrm{~V}$. After adding inductive load at $0.05 \mathrm{~s}$, the system changes, but the error can hardly be seen, so the stability of the system is strong.

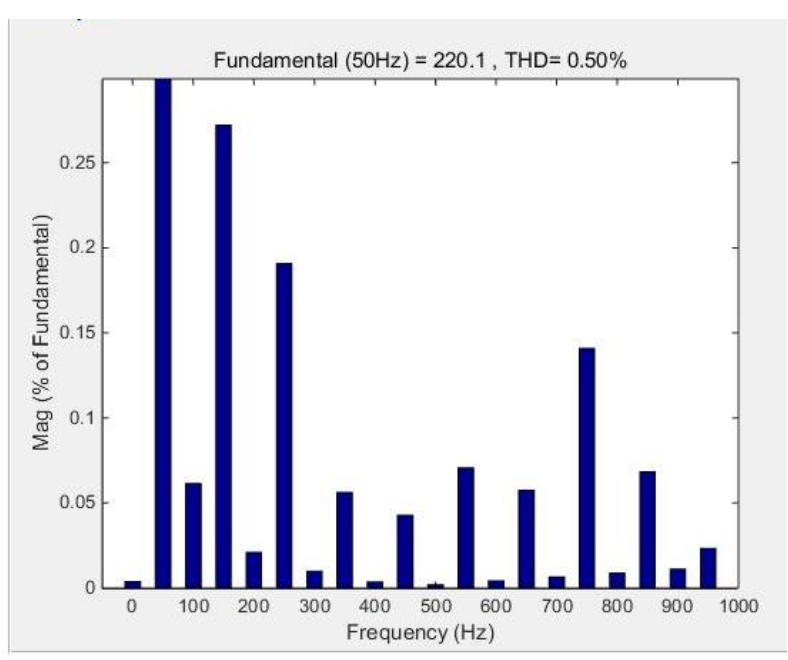

Figure 7: Analysis of Total Harmonic

As shown in Figure, the output voltage THD of the PI neuron control system reaches $0.50 \%$, the harmonic is small, and the waveform distortion is small too, which meets the requirements of the voltage output. The PI neuron control inverter can make the waveform follow the amplitude and phase of the reference voltage well, and ensure the frequency and phase of the current and voltage are consistent.

\section{CONCLUSION}

An improved PI neurons control algorithm is designed, which can change the weights in real time by the feedback of voltage and current, combined with neural network, according to the load situation to adapt to sudden load and nonlinear load. The experimental results show that the algorithm can constantly look for the parameters that adapt to the current system by online-learning, which solves the problem that the PI parameters of the traditional double closed loop algorithm need to be manually adjusted. The steady-state error of the system is smaller than that of the traditional PI control method. It has better adaptability and strong anti-interference ability when facing the changing system, and is more suitable for the complex system of photovoltaic grid connected.

\section{ACKNOWLEDGMENTS}

Project Supported by Youth Fund of Guangxi Science and Technology Department (2016GXNSFBA380094), Key Projects of Guangxi Education Department (ZD2014064).

\section{REFERENCES}

[1] Saritha, N., Jamuna, V., Nanthini, N. 2014. Power Quality Problems in Pv Fed Grid Connected Inverter. Applied Mechanics and Materials, 3407, 147-151.

[2] Yee, M.M., Sirisamphanwong, C. 2016. Analysis of The Impact of Distributed Grid-Connected Pv System on Power Quality Of The Electrical Distribution Network. Applied Mechanics and Materials, 4093, 124-129.

[3] Li, X., Pan, Q., He, K. 2012. Modeling and Analysis of Harmonic in The Mine Hoist Cnverter Based on Double Closed-Loop Control. Journal of Computers, 7, 1353-1360.

[4] Shahcheraghi, A., Piltan, F., Mokhtar, M., Avatefipour, O., Khalilian, A. 2014. Design A Novel Siso Off-Line Tuning of Modified Pid Fuzzy Sliding Mode Controller. International Journal of Information Technology and Computer Science (Ijitcs), 6, 72-83.

[5] Du, Y.P., Wang, N. 2004. A Pid Controller with Neuron Tuning Parameters for Multi-Model Plants. International Conference on Machine Learning and Cybernetics, 6, 3408-3411.

[6] Wu, Z.Q., Xu, C.H., Yang, Y. 2017. Adjustable Pid Control Based on Adaptive Internal Model and Application in Current Shared Control of Multi Inverters. Journal of The Franklin Institute, 354, 2699-2711.

[7] Ying, Y.Q., Lu, J.G., Chen, J.S., Sun, Y.X. 2012. Pidnn Based Intelligent Control of Ignition Oven. Advanced Materials Research, 1536, 493-497. 
[8] Liu, T.K., Juang, J.G.A. 2009. Single Neuron Pid Control for Twin Rotor Mimo System. Ieee/Asme International Conference on Advanced Intelligent Mechatronics, 186-191
[9] Zhang, Y.G., Yong, K., Liu, L. M., Jian, C. 2007. Improved Double CloseLoop Control System for Shunt Inverter of Upfc. Proceedings of The Csee, $27,40-46$. 